\title{
ENSEÑNANA VIRTUAL DE LAS CIENCIAS EMPRESARIALES EN PANDEMIA: DESAFÍOS Y RETOS
}

\section{VIRTUAL TEACHING OF BUSINESSSCIENCES IN A PANDEMIC: CHALLENGES AND CHALLENGES}

\author{
Henry Orlando Luna Pereira ${ }^{1}$ \\ Gerson Rueda Vera ${ }^{2}$ \\ William Rodrigo Avendaño Castro ${ }^{3}$
}

UFPS

\section{RESUMEN}

La presente investigación tuvo como objetivo determinar los retos y desafíos de las recientes iniciativas de enseñanza virtual como resultado de la pandemia COVID-19 desde la perspectiva de los profesores universitarios de ciencias empresariales de una universidad pública de la ciudad de Cúcuta (Colombia). La investigación tuvo un enfoque cuantitativo enmarcado en el paradigma empírico-analítico y un diseño no experimental-transversal. La muestra estuvo integrada por 75 profesores. El instrumento

1 Doctor en Ciencias Administrativas, UESR. Docente investigador, Universidad Francisco de Paula Santander. Correo electrónico: henryorlandolp@ufps.edu.co Orcid: https://orcid.org/0000-0003-2741-9170

2 Doctor (c) en Educación, Universidad Pedagógica Experimental Libertador. Docente investigador, Universidad Francisco de Paula Santander. Correo electrónico: gersonruedavera@ufps.edu.co. Orcid: https://orcid. org/0000-0001-9032-7100

3 Doctor en Ciencias Sociales y Humanas, Pontificia Universidad Javeriana. Docente investigador, Universidad Francisco de Paula Santander. Correo electrónico: williamavendano@ufps.edu.co. Orcid: 00000002-7510-8222 utilizado fue un cuestionario tipo likert de 5 alternativas y apoyada con preguntas abiertas. Los resultados denotan la adaptación al desafío de los docentes a una enseñanza con integración de las TIC, hacia procesos formativos y luego basada en la Web, que circunscribe autoaprendizaje y aprendizaje conectado. Se concluye que el reto es usar herramientas tecnológicas y al mismo tiempo hacerlo en la gestión y organización de la enseñanza, construcción de comunidades de aprendizaje, comunicación y estrategias de enseñanza.

\section{PALABRAS CLAVE}

Enseñanza virtual, ciencias empresariales, COVID-19.

\section{ABSTRACT}

The objective of this research was to determine the challenges and challenges of recent virtual teaching initiatives as a result of the COVID-19 
pandemic from the perspective of business science university professors from a public university in the city of Cúcuta (Colombia). The research had a quantitative approach framed in the empirical-analytical paradigm and a non-experimental-cross-sectional design. The sample consisted of 75 teachers. The instrument used was a Likert-type questionnaire with 5 alternatives and supported by open questions. The results denote the adaptation to the challenge of teachers to teaching with integration of ICT, towards training processes and then based on the Web, which circumscribes self-learning and connected learning. It is concluded that the challenge is to use technological tools and at the same time to do so in the management and organization of teaching, construction of learning communities, communication and teaching strategies.

\section{KEYWORDS}

Virtual teaching, business sciences, COVID-19.

\section{INTRODUCCIÓN}

Las naciones al implementar medidas de bloqueo en sus poblaciones y en la dinámica económica, social y profesionales, internadas o paralizadas a causa de la enfermedad por un nuevo coronavirus (COVID-19) que se transmite de persona a persona y con una gran propagación global, interrumpieron las actividades académicas a nivel mundial a más de 1.600 millones de estudiantes por el COVID-19 (Naciones Unidas, 2020). El mundo cambiante y las necesidades emergentes llevaron a los profesores y a las instituciones educativas a emplear estrategias con el fin de sobrellevar la crisis y las transformaciones con las tecnologías. Las instituciones educativas y las universidades han estado efectuando enseñanza remota, enseñanza virtual, aprendizaje en línea, entre otras modalidades de educación.
Desde la posición de Rueda, Luna y Avendaño (2021, p.323), las TIC "ofrecen a los docentes múltiples opciones para seguir ejerciendo su labor educativa durante el distanciamiento social generado por la pandemia de COVID-19", aunque Cardona (2021) afirma que las Instituciones de Educación Superior con modelos tradicionales, desplazaron este modelo de enseñanza presencial por estrategias que aún están lejos de concebirse como modelos de educación virtual. El común denominador en medio de la pandemia es una forma de educación apoyada en TIC con encuentros sincrónicos, más no una educación de tipo virtual que implicaría la construcción de nuevas realidades, aunque en el lenguaje común se emplea el término educación virtual para caracterizar estas nuevas realidades en lo educativo.

Aun así, es de esperarse que la docencia enfrente desafíos en la emergencia educativa, ya que la tecnología y la virtualidad aplicada a la educación, en palabras de Rama (2007), trae consigo cambios propios de la era de la globalización en sus estructuras sociales y académicas, donde no solo demandan tema de calidad, cobertura, internacionalización o financiamiento, sino también, flexibilidad con los estudiantes y con sus formas de estudio cada vez más diversas, necesidad de una fuerza laboral capacitada digitalmente y métodos efectivos para desarrollar habilidades.

De repente, nos encontramos en una situación en la que no se puede contrastar los desafíos, retos y limitaciones que se venían dando en las investigaciones propias del ámbito virtual. Pero esto no quiere decir que no se haga una diferenciación entre educación virtual y la educación presencial, sus estudiantes, docentes y el personal de apoyo, orientación y planificación docente que desempeñan un papel clave en la planificación e implementación de los cursos o asignaturas. Sin embargo, la modalidad de educación virtual y a distancia, 
fundamentalmente en soporte digital, vino a ofrecer soluciones de emergencia a dicha crisis de la educación presencial (García Aretio, 2021).

En esta dirección se presenta un contexto, de oportunidades, retos, desafíos y limitaciones. Según el punto de vista de García Aretio (2021), esta pandemia se ha convertido en un catalizador para que las instituciones educativas busquen soluciones innovadoras en un período de tiempo relativamente corto. A esta narrativa, se han adicionado experiencias iniciales de la enseñanza y evaluación a distancia en época de pandemia (Spector et al., 2020), así como las dificultades educativas encontradas en el periodo de confinamiento en el uso de plataformas digitales (Burgos et al., 2021). A nivel nacional, Cardona (2021) indagó sobre las percepciones de docentes frente al cambio en tiempos de pandemia, donde encontró que se evidencian la necesidad de implementar modelos de aprendizaje en entornos virtuales, ya que en opinión de Avendaño et al., (2021) el docente universitario ante la emergencia educativa, ha adaptado las TIC en los procesos de enseñanza.

Lo anterior muestra, por una parte, las prácticas educativas que se ampararon de la transformación digital $y$, por otro lado, una adaptación forzada a un entorno remoto, virtual o en línea. Numerosos son los retos, limitaciones y cambió desde distintas instituciones educativas, porque asumir la enseñanza en la virtualidad o educación virtualizada, según Lassos et al., (2017, p.23), supone "las relaciones entre planeación, diseño, desarrollo y evaluación [...] la virtualización sugiere acción y creación, la pedagógica, indica un ejercicio didáctico constante para la estructuración de estrategias metodológicas".

Desde el punto de vista académico, la enseñanza virtual se basa en una comunicación didáctica mediada entre el profesor (institución) y el estudiante que está ubicado en espacio diferente con el uso de tecnologías (García Aretio, L, 2001). Por eso se da un proceso dialógico en el aprendizaje (Martínez Uribe, 2008), y al mismo tiempo, la enseñanza virtual viene de un proceso generacional donde ha pasado desde una educación multimedia, así como una enseñanza basada LMS con integración de las TIC a los procesos formativos, y luego basada en la Web (learning 2.0 y B-learning), la cual incluye autoaprendizaje, aprendizaje conectado, flexible, autónomo, abierto y en línea, aprendizaje activo, activo y colaborativo con integración de la Web 2.0 como blog, wiki, redes sociales, entre otros (Arboleda y Rama, 2013, García Aretio, 2003). En opinión de Avendaño et al., (2021) cambiar a la educación remota y en línea puede ser una modalidad para reducir la propagación del Covid-19, pero esta tendencia, asimismo, genera retos, desafíos y oportunidades para los docentes, incluidos aquellos que carecen de habilidades TIC para enseñar en la educación basada en Internet.

Por ende, este estudio propone un avance en torno al campo científico concerniente a los desafíos y retos en la enseñanza virtual durante las pandemias. El actual reto está en conseguir que los docentes reflexionen, indaguen y comprendan cómo los estudiantes de hoy están aprendiendo a partir de la presencia cotidiana de la tecnología (Oviedo, 2014). Por ello, es necesario explorar las dificultades que han tenido los docentes en sus procesos de docencia, así como la modalidad asociada a las TIC, prácticas de enseñanza, recursos. Es una necesidad considerar condiciones del profesorado universitario en tiempos de pandemia para la adaptación de su enseñanza (Álvarez et al, 2011).

Esto representa una oportunidad especial para quelas distintasfacultadesacadémicas examinen los retos que se presentan ante la enseñanza virtual luego de la pandemia y garanticen una educación de calidad. En lo práctico, identificar 
desafíos para disminuir las condiciones adversas en la crisis y también brindar una oportunidad para que las universidades utilicen las tecnologías apropiadas en la enseñanza. Por lo tanto, el presente estudio tiene como objetivo determinar los retos y desafíos de las recientes iniciativas de enseñanza virtual como resultado de la pandemia COVID-19 desde la perspectiva de profesores universitarios de ciencias empresariales de una Universidad pública de la ciudad de Cúcuta en Colombia.

\section{BASES TEÓRICAS: ENSEÑANZA VIRTUAL. ENTRE RETOS Y DESAFÍOS}

Para entender qué es la enseñanza virtual, primeramente, la enseñanza, tiene varios puntos de vista, y desde las diversas teorías didácticas se precisa de distintas maneras. En un principio, se postulaba que enseñar es transmitir conocimientos al estudiante. Por otro lado, enseñar es dejar que el alumno descubra el conocimiento. Otra postura indica que enseñar es guiar a los alumnos en su construcción del conocimiento o enseñar es construir el conocimiento junto con el educando. Como se observa existe un vínculo particular entre dos personas en la enseñanza, en el cual una de ellas hace algo para que la otra adquiera un conocimiento (Fairstein y Gyssels, 2003).

La enseñanza es una actividad que se planifica de acuerdo con una perspectiva propia del docente (Pratt, 2001), a fin de alcanzar ciertas intenciones previamente fijadas. Esto significa que enseñar es una actividad con intención. De manera que un docente no podría decir que no sabe por qué o para qué hace lo que hace. Sarmiento (2007) considera que la enseñanza es una actividad sociocomunicativa y cognitiva que dinamiza los aprendizajes significativos en ambientes ricos y complejos (aula, aula virtual, aula global o fuera del aula), síncrona o asíncronamente.
Con respecto a lo virtual, se entiende por virtual a un lugar, cosa, persona, etcétera, que no existe materialmente, sino digitalmente en el ciberespacio. Al usar las tecnologías en la educación, la enseñanza igualmente cumple con unas primicias, independientemente que se imparta una educación virtual. Entonces, la enseñanza virtual es una modalidad en la educación en la que el proceso de enseñanzaaprendizaje sucede en Internet. De allí, el uso de Internet es el medio principal de interacción en dicha educación. Lassos, Munévar, Rivera, \& Sabogal (2017, p. 22) señalan que "la educación virtual es la evolución de la educación a distancia, lograda por el desarrollo y fortalecimiento de la relación educación y tecnología". Lo anterior implica un gran reto y desafío para lo que enseñan con ayuda de la virtualidad, porque supone que pueden desconocer ciertas funciones de los tutores virtuales en la manera de enseñar con tecnología y de integrar la tecnología con el currículo y las estrategias.

En esencia, la educación virtual en opinión de Parra (2005) constituye un conjunto de dispositivos tecnológicos y pedagógicos que sirven como medio tanto a docentes como los otros agentes básicos, los estudiantes y los objetos de estudio que están distribuidos en espacios diferentes. Esto plantea unos retos especiales, diferentes a los de la educación presencial. Sanabria (2020) destaca que la enseñanza en la educación virtual -también Ilamada educación online-, alude a los procesos didácticos o de formación mediados por la tecnología.

Parafraseando a Henry \& Meadows (2008), los principios para la excelencia en la enseñanza en línea pudieran ser los siguientes:

1. El mundo virtual es un medio en sí mismo. No es solo el acceso al internet o a medios, sino que se incluyen los materiales en distintos formatos que tienen que ser desarrollados considerando la especificidad de las fortalezas y 
dinámicas de la web en función de lo pedagógico. No es que el estudiante revise los materiales, sino deben estar en función de la interacción y comunicación que se puedan establecer entre el estudiante, material cognitivo y el profesor. De hecho, esto da sentido al segundo principio que se presenta a continuación.

2. En el mundo virtual, "contenido" es un verbo. El autor destaca que la docencia en línea involucra mucho más que subir una serie de lecturas o el programa de una asignatura a un sitio web. Por ello, en la enseñanza virtual, el contenido debe tener como intención que conlleva a una acción (estrategia), promover las responsabilidades de los estudiantes con actividades interactivas.

3. La tecnología es un vehículo y no el destino. Refiere que en la enseñanza virtual los educadores deben ser críticos sobre las tecnologías utilizadas para el aprendizaje de los educandos. La selección de la tecnología está

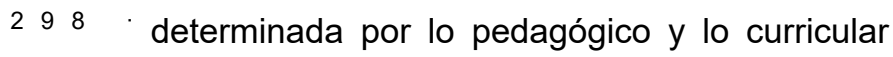
(Koehler \& Mishra, 2009).

4. La enseñanza por encima de la tecnología. La presencia del docente en la enseñanza virtual no está definida por la tecnología sino por la enseñanza, donde logran los resultados de aprendizaje esperados. Además, el educador está presente en función de la comunicación síncrona y asíncrona, realimentación efectiva, así como formativa, en el cual establece los vínculos necesarios para el proceso de enseñanza aprendizaje. lo cual da sentido de comunidad y presencia social para alcanzar la excelencia en línea.

5. Interfaz. En la enseñanza virtual es necesario que los docentes dispongan los recursos necesarios y organizados para que los estudiantes puedan encontrar todo para aprender y con facilidad. De este modo, el syllabus en la enseñanza virtual es una guía de estudio y la herramienta que sitúa al estudiante a través del curso, con el cual se crea un vínculo entre este y elementos tales como contenido, tareas, actividades grupales, entre otros.

6. Evaluación y refinamiento continuo. Representa la revisión periódica y sistemática de todos los aspectos de la enseñanza virtual y los posteriores cambios y actualizaciones que se agregan como resultado de dicho proceso. La evaluación es esencial y debería abarcar al menos dos áreas importantes: efectividad en la enseñanza y eficiencia en impartir los cursos (Ellis \& Hafner, 2003).

Al observar estos principios, se infiere, por una parte, que el desarrollo de un entorno virtual requiere experiencia, tiempo y dinero, y por otro lado, que la tecnología y lo virtual en la enseñanza traerá un pensamiento educativo completamente nuevo, resolverá problemas que antes el docente no podía resolver y acarreará una serie de cambios importantes en la educación. Pero se debe resaltar el desafío que tiene el docente virtual para enseñar con tareas de aprendizaje y evaluación con los resultados de aprendizaje esperados con la tecnología sin centrarse en ella, pero esperando que apoye un aprendizaje profundo.

La epidemia del COVID-19 ha aumentado el desarrollo de la enseñanza virtual y ha brindado oportunidades de continuar con los procesos educativos. El reto en dar lugar a resultados de aprendizaje más justos, en cuanto a la accesibilidad de dispositivos e internet, mientras se disponen en la práctica el modelo didáctico que lleva a los estudiantes desde el nivel de intercambio de ideas y reflexiones a la construcción conjunta del conocimiento, referido a la presencia cognitiva (Garrison, Anderson y Archer, 2000), es una tarea que entraña dificultades en la enseñanza virtual a través del debate en los foros con recursos digitales y otras tecnológicos que posibilitan nuevos modos de intercambios y de actividades sociales que antes no habían sido pensadas en el aprendizaje, 
que hoy es conectivo (Fernández-Sánchez \& Valverde-Berrocoso, 2014; Siemens, 2006).

Asu vez, desde esta perspectiva, Siemens (2006) se contrapone al vínculo, ya que argumenta que el aprender se da por conexiones que se forman naturalmente a través de un proceso de asociación, y no se construyen a través de algún tipo de acción intencional, porque en el conectivismo acoge un enfoque fuertemente inclinado hacia el conocimiento, los significados, las comunidades y las redes, entornos de aprendizaje personal (PLE), en la cual se crean conexiones con artefactos y con personas con las que una persona interactúa y sus espacios. De allí otro reto y desafío del docente al entrar en la enseñanza virtual y fundamentar el aprendizaje en un plan de enseñanza aprendizaje conectivo.

En fin, la enseñanza virtual estará determinada de acuerdo al modelo y las prácticas pedagógicas que se adopten y los desafíos en tiempo en pandemia. También incluyen el acceso a internet y donde viven los estudiantes por las características interacciones comunicativas estudiante-estudiante y estudiante-profesor a través de ordenadores y redes telemáticas conectados. Esto plantea unos retos específicos, diferentes a los de la educación presencial porque en la pandemia tanto docentes como discentes van aprendiendo y utilizando la tecnología en su rutina de clases diferente a la acostumbrada magistralidad que impera en la enseñanza.

No obstante, hoy las universidades buscan orientar el proceso hacia el "aprenderaprender", ya sea con modelos tradicionales o virtuales. Entendiendo el aprendizaje como el resultado de la construcción activa del sujeto sobre el objeto de aprendizaje, pues, las estrategias didácticas buscan un papel más activo del estudiante. Al respecto, Avendaño et al., (2017) señalan que se hace imperiosa una revisión de la didáctica de la enseñanza, pues se realza la necesidad de capacitar al profesor universitario en aspectos pedagógicos con una didáctica globalizadora, centrada en los procesos y los agentes de formación, en la potenciación de las tecnologías como medios y materiales didácticos innovadores, para lograr que sus alumnos construyan críticamente el conocimiento necesario y adquieran las habilidades para transformarlo o crearlo a fin de fortalecer el programa de ciencias empresariales -administración de empresas, contaduría pública y similares-.

\section{METODOLOGÍA}

\subsection{Enfoque y tipo de investigación}

La investigación tuvo un enfoque cuantitativo de tipo descriptivo, el cual se caracteriza por reconocer las propiedades, características y los perfiles de personas, grupos, comunidades, procesos, objetos o cualquier otro fenómeno que se someta a un análisis (Hernández Sampieri et al., 2014). Además, esta indagación tuvo un diseño no experimental de corte transversal. Por ende, se tomó información en un momento específico que identifica los retos y desafíos de la enseñanza virtual originados por la pandemia del coronavirus (COVID-19) en docentes de la una Facultad de Ciencias Empresariales de una universidad pública en la ciudad de Cúcuta (Colombia). Considerando los anteriores planteamientos, la investigación se desarrolló en tres fases: 1) diseño de la investigación, 2) recolección de información, y 3) análisis y desarrollo.

\subsection{Población y muestra}

La población a la cual se orientó el estudio estuvo conformada por un conjunto profesores de una Facultad de Ciencias Empresariales con características comunes (que imparten enseñanza presencial) y queda delimitada por el problema y por los objetivos del estudio (Arias, 2012). Por ello, se opto por una muestra no probabilística -de carácter intencional-, ya que 
se seleccionó directa e intencionadamente los docentes que cumplen con esas condiciones antes descritas y decidieron participar voluntariamente en el estudio.

Se seleccionaron para la muestra un total de 75 individuo (docentes): 19 sujetos imparten enseñanza en el programa de administración de empresas $(25,3 \%), 33$ docentes pertenecen a la carrera de contaduría pública $(44,0 \%)$, y 23 profesionales que enseñan en el programa de comercio internacional $(30,7 \%)$.

\subsection{Instrumento de recolección de la información y variables de análisis}

Para la recopilación de la información se elaboró un cuestionario, el cual fue auto-administrado de manera online. Estuvo estructurado con 31 preguntas con varias opciones de respuesta, así como con algunas preguntas abiertas. Se consideró favorable organizarlo en tres bloques que mostraran todos los aspectos afines con los objetivos planteados. El primer bloque lo conforman las preguntas de carácter sociodemográfico: edad, sexo, grado de estudios, años de experiencia docente en educación superior, estrato socioeconómico, entre otras. El segundo bloque estuvo referido a las condiciones socio-tecnológicas: conexión a internet, equipos y medios, ambiente en el lugar de conexión, recursos económicos y conocimientos sobre el uso de tecnologías. El último bloque se enfocó en examinar la enseñanza: modalidad asociada a las TIC, prácticas de enseñanza, metodologías implementadas, materiales y medios, incremento de tiempos para la docencia.

\subsection{Procesamiento de los datos}

Los datos recolectados fueron organizados y tabulados en hojas de cálculo del programa Excel para un análisis estadístico de tipo descriptivo. Así, se efectuó una exploración descriptiva de los datos obtenidos del cuestionario a partir de las frecuencias por ítems y opciones. Para las preguntas abiertas se empleó el diseño narrativo, donde el investigador recaba datos sobre las experiencias para describirlas y analizarlas (Hernández-Sampieri \& Mendoza, 2018), a partir de la recopilación de diversas opiniones, anécdotas y experiencias basadas en la enseñanza virtual durante la pandemia.

\section{RESULTADOS Y DISCUSIÓN}

A continuación, se hace una descripción de los resultados obtenidos. El 42,7\% de los docentes encuestados eran mujeres y un $57,3 \%$ hombres. En cuanto a la edad, se evidenció que el mayor grupo de estos profesionales lo conforman un $30,7 \%$ de los educadores que tienen 56 años o más, seguidos de los que se encuentran entre 41 y 45 años $(20,0 \%)$ y $46-50$ años $(16,0 \%)$. El resto, un 13,3\%) tienen entre 36 y 40 años, los que están entre 51 y 55 años representan el $9,3 \%$. Entretanto, otro $6,7 \%$ están comprendidos en 30 y 35 años y el menor grupo son los menores de 30 años $(4,0 \%)$

De los cuales, el $22,7 \%$ poseen un grado de estudios completado de especialista. Mientras que el 69,3\% tienen títulos de magister. Entretanto que el $15,3 \%$ poseen doctorados y con postdoctorado un 2,7\%. En lo referente a los años de experiencia en educación superior, se conoció que el $14,7 \%$ tiene un tiempo de entre uno a 3 años impartiendo la enseñanza dentro de la universidad. Mientras que un $17,3 \%$ manifestó tener entre 4 a 6 años de experiencia de docencia universitaria. El resto de los encuestados, manifiestan que los años de práctica que han ejercido la enseñanza superior está entre 7 a 10 años (12,0\%); entre 11 a 15 años $(14,7 \%)$; entre 16 a $20(13,3 \%)$. Otro, $14,7 \%$ tienen entre 21 a 25 años y por último los que tienen 26 o más años (13,3\%).

De este grupo, el $82,7 \%$ son docentes de cátedra, un $9,3 \%$ son de planta y otro $8,0 \%$ son docentes ocasionales, los cuales imparten la enseñanza en la facultad de ciencias 
empresariales en los semestres 1 o 2 un $(2,7 \%)$, los que enseñan en los semestres 3 o 4 (14,7\%). Mientras que, un $16,0 \%$ da clases entre los semestres 5 o 6; otro grupo conformado por un $21,3 \%$ en los semestres 7 o 8 . El resto, un $6,7 \%$ en los últimos semestres ( 9 o 10) y otro $38,7 \%$ entre los distintos semestres que van del primero hasta el final de la carrera. De los cuales están distribuidos socioeconómicamente en los siguientes estrados: un 13, 3\% pertenecen al estrato dos; un $38,7 \%$ al tres, otro $38,7 \%$ al cuatro, un $8,0 \%$ al cinco y un $1,3 \%$ del estrato socioeconómico seis

Una vez estimadas estas informaciones se tomaron en cuenta aspectos relacionados con las condiciones socio-tecnológicas (ver tabla 1)

Tabla 1. Conexión a internet

\begin{tabular}{|c|c|c|c|}
\hline Ítem & Opciones & No & Porcentaje \\
\hline 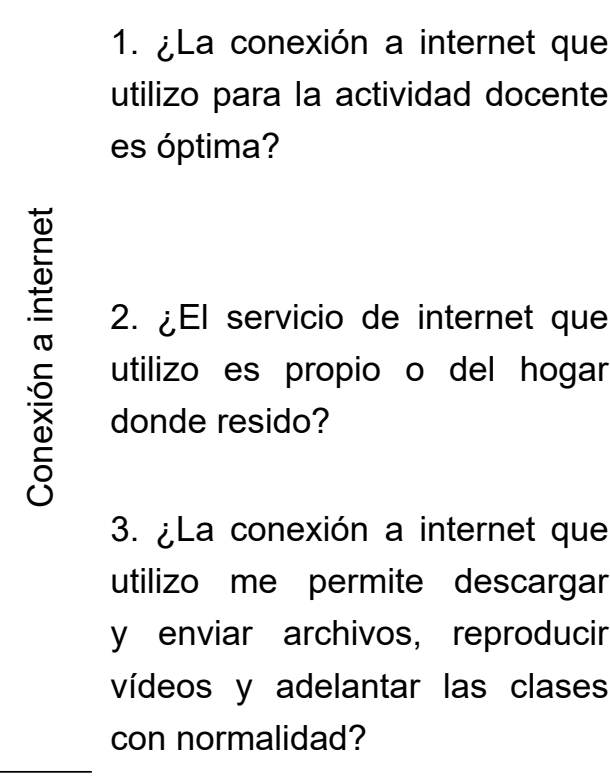 & $\begin{array}{l}\text { Muy de acuerdo } \\
\text { Algo de acuerdo } \\
\text { Ni de acuerdo ni en desacuerdo } \\
\text { Algo en desacuerdo } \\
\text { Muy en desacuerdo } \\
\text { Muy de acuerdo } \\
\text { Algo de acuerdo } \\
\text { Ni de acuerdo ni en desacuerdo } \\
\text { Algo en desacuerdo } \\
\text { Muy en desacuerdo } \\
\text { Muy de acuerdo } \\
\text { Algo de acuerdo } \\
\text { Ni de acuerdo ni en desacuerdo } \\
\text { Algo en desacuerdo } \\
\text { Muy en desacuerdo }\end{array}$ & $\begin{array}{l}48 \\
21 \\
2 \\
4 \\
0 \\
68 \\
6 \\
0 \\
1 \\
0 \\
52 \\
19 \\
3 \\
1 \\
0\end{array}$ & $\begin{array}{l}64,0 \% \\
28,0 \% \\
2,7 \% \\
5,3 \% \\
0,0 \% \\
90,7 \% \\
8,0 \% \\
0,0 \% \\
1,3 \% \\
0,0 \% \\
69,3 \% \\
25,3 \% \\
4,0 \% \\
1,3 \% \\
0,0 \%\end{array}$ \\
\hline
\end{tabular}

Fuente: elaboración propia

Los datos registrados en la tabla 1, muestran que el ítem 1, determinó entre las alternativas muy de acuerdo y algo de acuerdo que $92,0 \%$ de los docentes que imparten clases en la facultad de ciencias empresariales poseen una óptima conexión a internet para las actividades de la enseñanza virtual. Mientras que en el ítem 2, el $98,7 \%$ de estos profesionales utilizó el servicio de internet en su propio hogar donde reside. EI hallazgo en el ítem 1, esté en concordancia con los resultados del ítem 3 , ya que logró verificar que $94,6 \%$ de los encuestados manifestaron que la conexión a internet que utilizo permite descargar y enviar archivos, reproducir vídeos y adelantar las clases con normalidad.

Atendiendo los resultados 1,2 y 3 , se observa que un $8 \%$ de los docentes no se está satisfecho la conexión a internet para realizar sus actividades de manera recomendable, además un 1,3\% de ellos no utilizó el servicio de internet en el hogar que residen, de allí que ese mismo porcentaje estuvo al en desacuerdo sobre adelantar sus clases con normalidad al descargar archivos y reproducir videos. Bajo estos parámetros, se considera que para aquellos que no tienen 
acceso a Internet, la educación puede estar fuera de su alcance. De hecho, la brecha digital perpetúa las desigualdades. Los docentes que se encuentran en bajos estratos, así como zonas rurales y de bajos ingresos están aún más rezagados que sus pares y se encuentran con muy pocas oportunidades de cerrar la brecha.

En esta dirección, la enseñanza virtual tiene grandes desafíos para los docentes que no tienen fácil acceso a Internet de alta velocidad, puesto que podría afectar la acción y creación, la, pedagógica, así como el ejercicio didáctico (Lassos et al., 2017). De allí que el reto será de cómo el docente en su rol de mediador del conocimiento puede ayudar a sus estudiantes a resolver las complicaciones que se pudieran dar entre la información y el conocimiento cuando su conexión de internet no es óptima para las distintas actividades planificadas, porque algunos profesores se encuentran en una muy buena posición para dar el salto a la educación en línea pero otros no.

Tabla 2. Equipos y medios

\begin{tabular}{|c|c|c|c|}
\hline Ítem & Opciones & No & Porcentaje \\
\hline 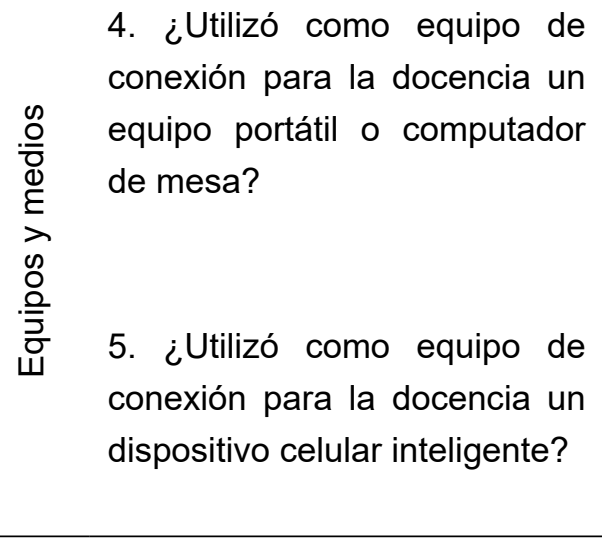 & $\begin{array}{c}\text { Muy de acuerdo } \\
\text { Algo de acuerdo } \\
\text { Ni de acuerdo ni en desacuerdo } \\
\text { Algo en desacuerdo } \\
\text { Muy en desacuerdo } \\
\text { Muy de acuerdo } \\
\text { Algo de acuerdo } \\
\text { Ni de acuerdo ni en desacuerdo } \\
\text { Algo en desacuerdo } \\
\text { Muy en desacuerdo }\end{array}$ & $\begin{array}{r}66 \\
8 \\
0 \\
1 \\
0 \\
18 \\
17 \\
7 \\
7 \\
\\
26\end{array}$ & $\begin{array}{r}88,0 \% \\
10,7 \% \\
0,0 \% \\
1,3 \% \\
0,0 \% \\
24,0 \% \\
22,7 \% \\
9,3 \% \\
9,3 \% \\
34,7 \%\end{array}$ \\
\hline
\end{tabular}

Fuente: elaboración propia

La tabla 2, muestran en el ítem 4, que el $98,7 \%$ entre las alternativas muy de acuerdo y algo de acuerdo dijeron que utilizaron un equipo portátil o computador de mesa de conexión para la docencia. Mientras que en iguales opciones en el ítem 5, se determinó que el 46,7\% Utilizó como equipo de conexión un dispositivo celular inteligente para la docencia. Los resultados de los ítem 4 y 5 , respaldan las opiniones consideradas en los párrafos anteriores respecto a los ítem 1, 2 y 3, que algunos educadores no tienen las condiciones adecuada para hacer la enseñanza virtual, ya que un $1,3 \%$ no posee equipos tecnológicos para la docencia virtual y más del $50 \%$ no utilizan dispositivos celulares inteligente, algo que podría ayudar al proceso dialógico en el aprendizaje (Martínez Uribe, 2008) y por ende, a la formación. Lo que se contrapone a las sugerencias de Parra (2005), que la educación virtual requiere un conjunto de dispositivos tecnológicos que sirven como medio tanto a docentes a estudiantes, así como la adaptación a las TIC en los procesos de enseñanza que según Avendaño et al., (2021) dicen que los docente universitario vienen realizando ante la emergencia educativa. 
Tabla 3. Ambiente en el lugar de conexión

\begin{tabular}{|c|c|c|c|}
\hline Ítem & Opciones & No & Porcentaje \\
\hline 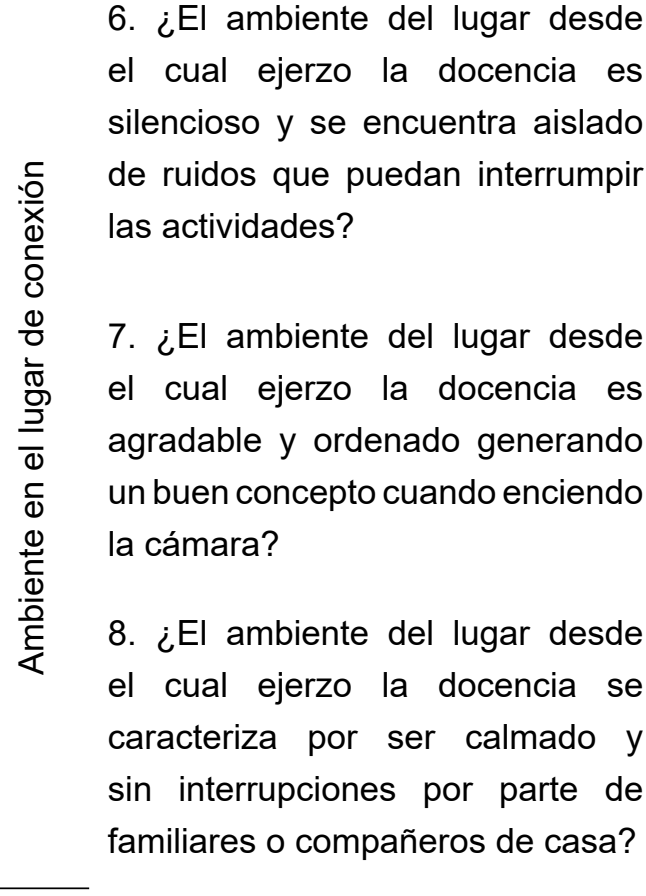 & $\begin{array}{l}\text { Muy de acuerdo } \\
\text { Algo de acuerdo } \\
\text { Ni de acuerdo ni en desacuerdo } \\
\text { Algo en desacuerdo } \\
\text { Muy en desacuerdo } \\
\text { Muy de acuerdo } \\
\text { Algo de acuerdo } \\
\text { Ni de acuerdo ni en desacuerdo } \\
\text { Algo en desacuerdo } \\
\text { Muy en desacuerdo } \\
\text { Muy de acuerdo } \\
\text { Algo de acuerdo } \\
\text { Ni de acuerdo ni en desacuerdo } \\
\text { Algo en desacuerdo } \\
\text { Muy en desacuerdo }\end{array}$ & $\begin{array}{r}39 \\
26 \\
5 \\
3 \\
2 \\
58 \\
16 \\
1 \\
0 \\
0 \\
47 \\
25 \\
1 \\
0 \\
2\end{array}$ & $\begin{array}{r}52,0 \% \\
34,7 \% \\
6,7 \% \\
4,0 \% \\
2,7 \% \\
77,4 \% \\
21,3 \% \\
1,3 \% \\
0,0 \% \\
0,0 \% \\
62,7 \% \\
33,3 \% \\
1,3 \% \\
0,0 \% \\
2,7 \%\end{array}$ \\
\hline
\end{tabular}

Fuente: elaboración propia

Los datos registrados en la tabla 3 , dan cuenta del ambiente en el lugar de conexión en el cual el docente imparte sus enseñanzas durante la pandemia. Donde se comprobó en el ítem 6 , que $86,7 \%$, de los encuestados expresaron (entre las alternativas muy de acuerdo y algo de acuerdo) que el ambiente seleccionado para ejercer la docencia fue un lugar silencioso y aislado de ruidos para que las actividades no fueran interrumpidas. Asimismo, se conoció en el ítem 7, entre las mismas opciones que el $98,7 \%$ de los encuestados que el lugar escogido fuera agradable y ordenado para generar un buen concepto cuando esté en la cámara en el ejercicio de la docencia. Entretanto, que el ítem 8, de verificó que un $96,0 \%$ de los encuestados en dichas opciones el ambiente del lugar elegido para realizar la docencia se caracterizó por ser calmado y sin interrupciones por parte de familiares o compañeros de casa.
Esto indica que un grupo pequeño de docentes (ítem 6 con un 13,4\%; Otro 1,3\% en el ítem 7 y un $4,0 \%$ en el ítem 8 ) encontraron dificultades en el ambiente y lugar para ejercer la enseñanza de manera virtual. Los resultados concuerdan y son afines a lo preguntado entre los ítems del 1 al 5. Por lo tanto, el desafío y el reto la enseñanza virtual durante la pandemia es evitar estas desigualdades en pro de los estudiantes, ya que las condiciones del ambiente al momento de educar y establecer los vínculos necesarios en la enseñanza, podría interferir la actividad pedagógica, sociocomunicativa y cognitiva en la que se dinamizan los aprendizajes (Sarmiento, 2007), al mismo tiempo, un ambiente inapropiado obstaculiza el proceso y por ende uno de los principios establecidos en la excelencia de la enseñanza en línea propuesto por Henry \& Meadows (2008) la presencia del docente en función de la comunicación síncrona 
y asíncrona, realimentación efectiva, así como formativa.

Tabla 4. Recursos de Imagen y audio.

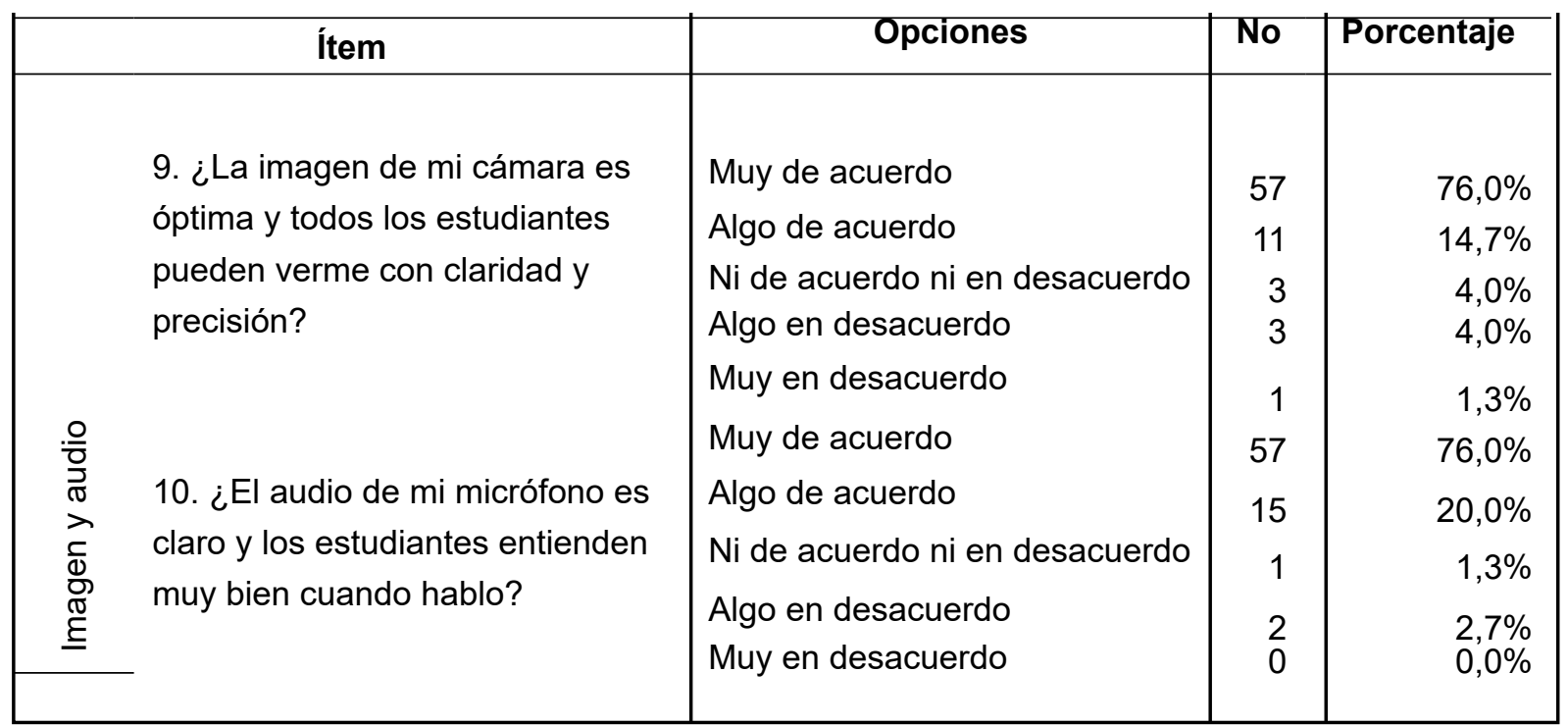

Fuente: elaboración propia

En la presente tabla 4, se encontró que en el ítem 9 , el $90,7 \%$ de los docentes de ciencias empresariales encuestados presentaron una imagen en sus cámaras web de manera óptima para que los estudiantes pudieran verlo con claridad. Mientras que en el ítem 10, el 96,0\% manifestaron que el audio de los micrófonos fue claro y los estudiantes entendían cuando hablaba. Estos resultados encontrados demuestran que los docentes buscan establecer vínculos con sus estudiantes de modo síncrono, ya que la enseñanza está por encima de la tecnología (Henry \& Meadows, 2008) para la prestancia de la enseñanza virtual. De allí, observa un reto de estos docentes para apoyar la motivación académica, por ello, las intervenciones sincrónicas (con cámara y audio) crean y mantienen un vínculo significativo con los estudiantes.

Tabla 5. Recursos económicos

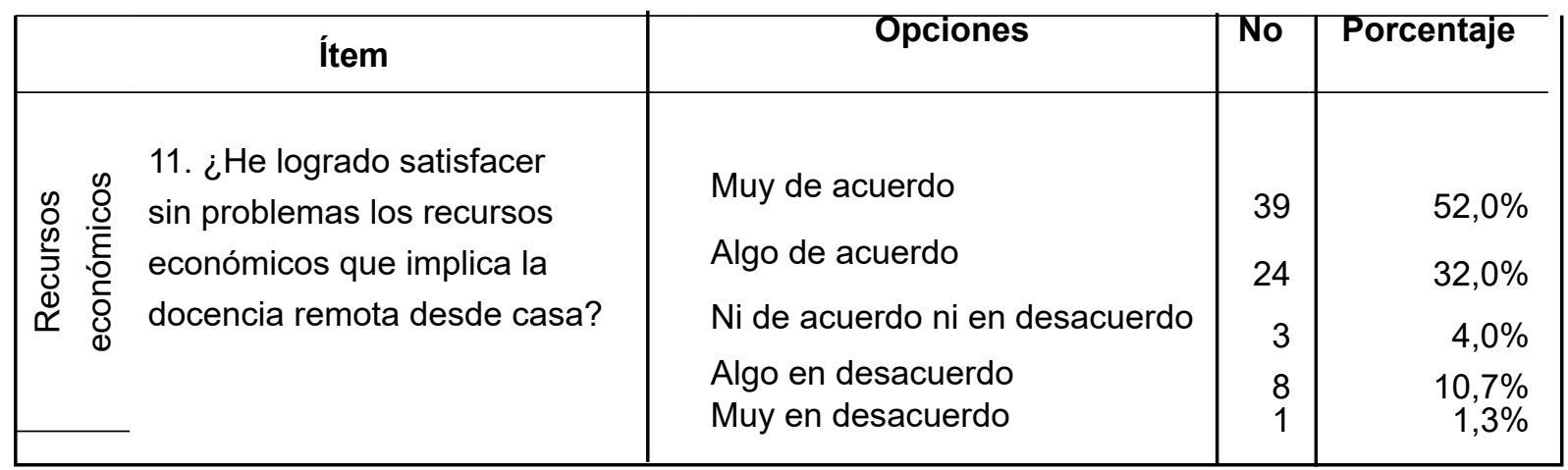

Fuente: elaboración propia 
La tabla 5, determina los recursos económicos que implica la docencia remota desde casa, logrando conocer que entre las alternativas muy de acuerdo y algo de acuerdo, el $84 \%$ de los encuestados manifestaron que lograron satisfacer sin problemas financieros la enseñanza durante la pandemia. Mientras que un $12,0 \%$ dijeron estar algo en desacuerdo y muy en desacuerdo con dicha situación financiera que involucró la enseñanza virtual y remota desde la casa. El Otro grupo, un 4,0\% permaneció en estado neutral $\mathrm{Ni}$ de acuerdo ni en desacuerdo.

Al observa este ítem, se deduce que la educación virtual no es una tarea fácil, ya que afrontar el reto y el desafío de enseñar con tecnología a veces no es equitativo y a la vez afecta el aprendizaje virtual y por ende a la calidad porque la educación virtual demanda temas de calidad, de cobertura y financiamiento (Rama (2007). La pandemia obligó a abordar un tema que ha estado debatiendo durante años, cómo integrar mejor el aprendizaje en línea o remoto en sus planes educativos. La mayor parte del proceso de enseñanza aprendizaje remoto implica tecnología. Pero la falta de acceso a Internet para que los profesores enseñen desde casa se volvió una tarea abrumadora, la enseñanza virtual en pandemia no es una solución completa. Si ve la tecnología como algo interesante que simplemente se incorpora a un plan de estudios existente, es un gran desafío y reto afrontar. De allí, que el entorno virtual requiere experiencia y tiempo, pero también recursos económicos para cumplir con excelencia ciertos principios para la enseñanza en línea (Henry \& Meadows, 2008).

Tabla 6. Conocimientos sobre el uso de tecnologías

\begin{tabular}{|c|c|c|c|}
\hline Ítem & Opciones & No & Porcentaje \\
\hline 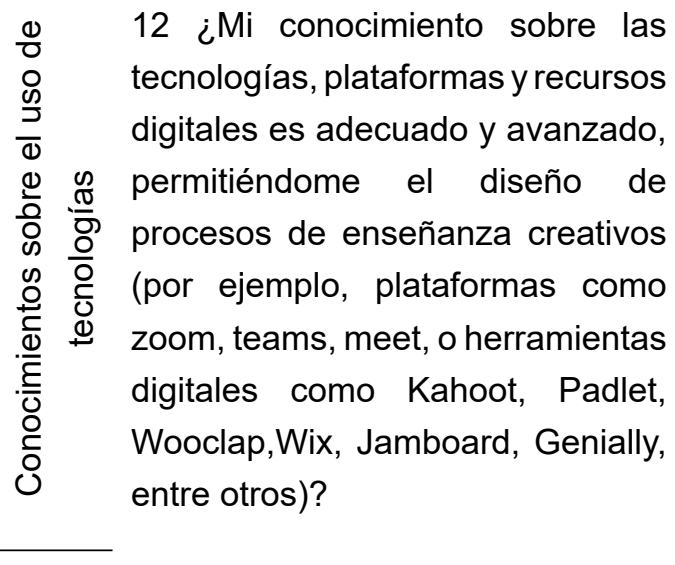 & $\begin{array}{l}\text { Muy de acuerdo } \\
\text { Algo de acuerdo } \\
\text { Ni de acuerdo ni en desacuerdo } \\
\text { Algo en desacuerdo } \\
\text { Muy en desacuerdo }\end{array}$ & 37 & $\begin{array}{r}49,3 \% \\
45,3 \% \\
4,0 \%\end{array}$ \\
\hline
\end{tabular}

Fuente: elaboración propia

En el ítem 12 de la tabla 6, los docentes encuestados estuvieron de acuerdo en un $94,6 \%$ en poseer conocimientos sobre las tecnologías, plataformas y recursos digitales es adecuado y avanzado, permitiéndole el diseño de procesos de enseñanza creativos, por ejemplo, plataformas como zoom, teams, meet, o herramientas digitales como Kahoot, Padlet, Wooclap,Wix, Jamboard, Genially, entre otros.El resto, el 1,3\% estuvo algo en desacuerdo y otro $4,0 \% \mathrm{Ni}$ de acuerdo ni en desacuerdo.

Los resultados de este ítem 12, indican que hay desigualdades en capacidades digitales. La 
enseñanza en el mundo físico se ha vuelto más pronunciadas en el mundo digital / virtual, incluso en la educación presencial. La educación en la pandemia, sólo reitera los que los autores han venido advirtiendo que cualquier docente que trabaje con tecnología digital, deben emplear una serie de herramientas con conocimientos del porqué las están usando. Al observar el grupo de aplicaciones digitales dispuesta en el ítem 12, se percibe este conocimiento tecnológico proporcionado dos interacciones en la enseñanza, por una parte, un dominio entre conocimiento y tecnología. En otras palabras, es la comprensión de lo que cambia en la enseñanza y el aprendizaje cuando se utilizan determinadas tecnologías. Esto refiere a lo que una tecnología en particular permite (o no permite), seguido de una relación con el aprendizaje y la enseñanza, de allí, la importancia de La selección de la tecnología (Herring, P. Mishra, and M. Koehler, 2008), con base a lo pedagógico y lo curricular.

\section{DIFICULTADES SOCIO-TECNOLÓGICAS DEL DOCENTE.}

En el Ítem 13, los resultados dan cuenta a la interrogante: ¿Qué dificultades ha tenido, usted, en los procesos de docencia con los estudiantes en estos tiempos de pandemia asociados a factores sociales o tecnológicos?

A pesar de que se sorteó de manera efectiva la emergencia educativa, la educación virtual no está exenta de dificultades. La enseñanza en la virtualidad a menudo tiende a producir una sensación de impotencia con respecto a la conexión a internet, empleo de herramientas digitales, dispositivos y equipos, a su vez, una desconexión entre los profesores y los participantes con respectos al aprendizaje. Al respecto, los docentes coincidieron en un $90,0 \%$ a los problemas de conexión de internet y señalan las siguientes dificultades:
Sujeto 17: No cuentan con óptima conectividad y sin computador.

Dificulta revisar materiales Sujeto11: La caída del internet, la intermitencia y desconocimiento de plataformas TIC.

Sujeto1: Lograr que los estudiantes se conecten, activen cámaras y participen. Sujeto20: Diferencias de conexión de la Internet entre estudiantes y docente.

Sujetos 22 y 39: La falta de interés y distracciones del ambiente externo.

Sujeto 10: Algunos estudiantes están haciendo otras actividades ya que ellos solo ponen la videollamada y apagan la cámara, entonces creo que el proceso de aprendizaje es nulo.

Al contrastar los resultados en los ítems del 1 al 12 con las respuestas dadas en el ítem 13, primeramente, se deduce que hay muchos obstáculos por superar en la implementación continua del aprendizaje virtual, especialmente en lo que respecta al acceso. Lo anterior muestra una realidad en la enseñanza virtual que no es circunstancial, sino por el contrario se acentúa en la dinámica educativa de la emergencia sanitaria al querer apoyar la educación con las TIC. Ello deja claro, varias cosas.

Primero, la visión y formación del docente de ciencias empresariales para asumir su rol de mediador con las TIC, donde la pandemia lo obligó a salir de la zona de confort con respecto a la enseñanza aprendizaje mediada con las tecnologías, Puesto que, un porcentaje igual o mayor al 90,0\% logró satisfacer las necesidades en la enseñanza en la pandemia. Segundo, algunos se enfrentan a un proceso que se siente estancado con respecto a los aprendizajes de sus estudiantes, donde se rompen los vínculos 
para establecer una conexión (Siemens, 2006). En otras palabras, dentro de la enseñanza virtual, más que un vínculo de enseñanza se convierte en un nodo de aprendizaje, pero el acceso a internet está dificultando un proceso conectivo en el intercambio de ideas y opiniones.

Tabla 7. Modalidad asociada a las TIC

\begin{tabular}{|c|c|c|c|}
\hline Ítem & Opciones & No & Porcentaje \\
\hline 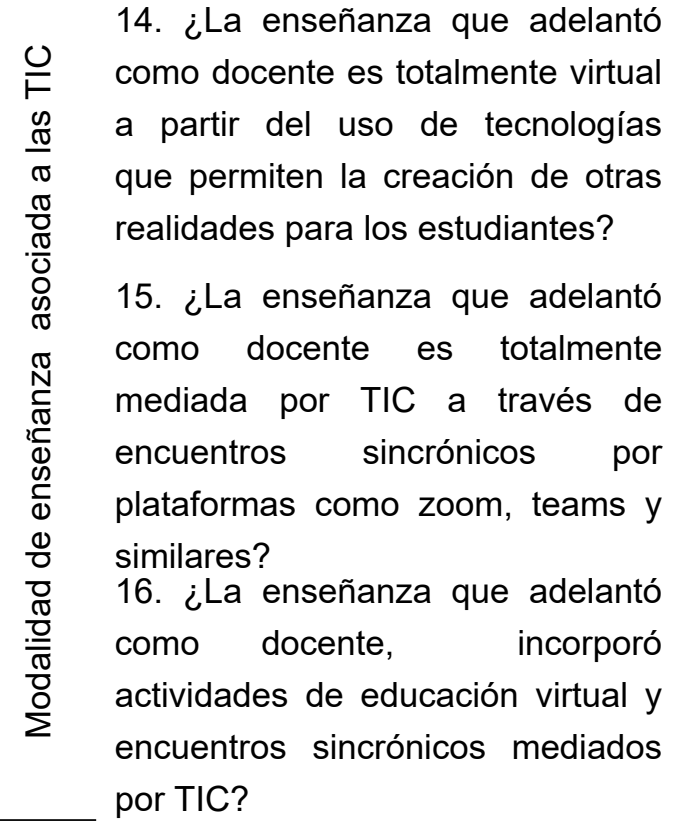 & $\begin{array}{l}\text { Muy de acuerdo } \\
\text { Algo de acuerdo } \\
\text { Ni de acuerdo ni en desacuerdo } \\
\text { Algo en desacuerdo } \\
\text { Muy en desacuerdo } \\
\text { Muy de acuerdo } \\
\text { Algo de acuerdo } \\
\text { Ni de acuerdo ni en desacuerdo } \\
\text { Algo en desacuerdo } \\
\text { Muy en desacuerdo } \\
\text { Muy de acuerdo } \\
\text { Algo de acuerdo } \\
\text { Ni de acuerdo ni en desacuerdo } \\
\text { Algo en desacuerdo } \\
\text { Muy en desacuerdo }\end{array}$ & $\begin{array}{r}60 \\
12 \\
2 \\
1 \\
0 \\
67 \\
8 \\
0 \\
0 \\
\\
0 \\
46 \\
22 \\
3 \\
2 \\
2\end{array}$ & $\begin{array}{r}80,0 \% \\
16,0 \% \\
2,7 \% \\
1,3 \% \\
0,0 \% \\
89,3 \% \\
10,7 \% \\
0,0 \% \\
0,0 \% \\
0,0 \% \\
61,3 \% \\
29,3 \% \\
4,0 \% \\
2,7 \% \\
2,7 \%\end{array}$ \\
\hline
\end{tabular}

Fuente: elaboración propia

La tabla 7, muestras los resultados concernientes a las modalidades de enseñanza asociada a las TIC, empleadas por los docentes de ciencias empresariales durante la pandemia, en la cual se comprobó que el $96,0 \%$ de los docentes encuestados (ítem 14) estuvieron de acuerdo en adelantar una enseñanza totalmente virtual a partir del uso de tecnologías que permiten la creación de otras realidades para los estudiantes. El resto, un 2,7 algo en desacuerdo y un $1,3 \%$ muy en desacuerdo. En lo referente al ítem 15 , se verificó que el $100 \%$, de los docentes encuestados están algo de acuerdo y muy de acuerdo en adelantar la enseñanza mediada por TIC a través de encuentros sincrónicos por plataformas como zoom, teams y similares. En cuanto al ítem 16, se determinó entre las alternativas muy de acuerdo y algo de acuerdo que un $90,6 \%$ adelantó como docente la incorporación de actividades de educación virtual y encuentros sincrónicos mediados por TIC. el resto, muy en desacuerdo $(2,7 \%)$ algo en desacuerdo $(2,7 \%)$ y un $4,0 \%$ permaneció neutral ni de acuerdo ni en desacuerdo.

Al observar estos resultados (ítems: 14,15 y 16), los docentes continuaron sus funciones donde la información se transmitió en una modalidad de enseñanza síncrona, pues el uso de herramientas como meet, zoom y team, fueron las preferidas por estos para interactuar en tiempo real y al mismo tiempo encontrarse en 
línea. Aunque, la pandemia, obligó aplicar una enseñanza remota, este período de enseñanza virtual durante el encierro debido al Covid-19, es un laboratorio para repensar la universidad en la era digital, el desafío para los docentes es el cambio en sus funciones tutoriales a través del debate en los recursos digitales y otras tecnológicos que posibilitan nuevos modos de intercambios y de actividades sociales que antes no habían sido pensadas (Fernández-Sánchez \& Valverde-Berrocoso (2014), así como, los retos y desafíos a la gestión del tiempo y la toma de notas como indicadores del compromiso cognitivo y conductual de los estudiantes que vienen asociadas a la modalidad síncrona, en la cual el docente deberá utilizar estrategias acorde a la modalidad.

Tabla 8. Prácticas de enseñanza

\begin{tabular}{|c|c|c|c|c|}
\hline & Opciones & No & Porcentaje \\
\hline \multirow{2}{*}{ 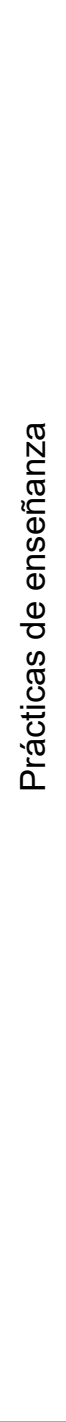 } & $\begin{array}{l}\text { 18. ¿He debido ajustar las prácticas de } \\
\text { enseñanza que comúnmente empleo como } \\
\text { resultado de la pandemia y la necesidad de } \\
\text { adelantar una educación mediada por TIC } \\
\text { o virtual? } \\
\text { 19. ¿Considero que hay objetos de } \\
\text { conocimiento y competencias que no } \\
\text { pueden ser trabajados de manera eficaz en } \\
\text { el marco de la educación virtual o mediada } \\
\text { Por TIC? }\end{array}$ & $\begin{array}{l}\text { Muy de acuerdo } \\
\text { Algo de acuerdo } \\
\text { Ni de acuerdo ni en desacuerdo } \\
\text { Algo en desacuerdo } \\
\text { Muy en desacuerdo } \\
\text { Muy de acuerdo } \\
\text { Algo de acuerdo } \\
\text { Ni de acuerdo ni en desacuerdo } \\
\text { Algo en desacuerdo } \\
\text { Muy en desacuerdo } \\
\text { Muy de acuerdo } \\
\text { Algo de acuerdo } \\
\text { Ni de acuerdo ni en desacuerdo } \\
\text { Algo en desacuerdo } \\
\text { Muy en desacuerdo }\end{array}$ & $\begin{array}{c}57 \\
15 \\
3 \\
0 \\
0 \\
56 \\
17 \\
1\end{array}$ & $\begin{array}{c}76,0 \% \\
20,0 \% \\
4,0 \% \\
0,0 \% \\
0,0 \% \\
74,7 \% \\
22,7 \% \\
1,3 \%\end{array}$ \\
\hline & $\begin{array}{l}\text { 20. ¿Cómo resultado de la imposición de } \\
\text { la educación virtual o mediada por TIC, } \\
\text { siento que mis prácticas de enseñanza han } \\
\text { mejorado? } \\
\text { 21. ¿Mi práctica de enseñanza se ubica } \\
\text { principalmente en:? }\end{array}$ & $\begin{array}{l}\text { Muy de acuerdo } \\
\text { Algo de acuerdo } \\
\text { Ni de acuerdo ni en desacuerdo } \\
\text { Algo en desacuerdo } \\
\text { Muy en desacuerdo } \\
\text { a) La pedagogía crítica enfocada en la } \\
\text { autonomía y emancipación del sujeto en } \\
\text { razón de las necesidades de su contexto en } \\
\text { lo social, político, económico y cultural. } \\
\text { b) la pedagogía cognitiva (constructivismo, } \\
\text { aprendizaje significativo, y similares). } \\
\text { c) Mi práctica de enseñanza se alimenta de } \\
\text { distintos enfoques pedagógicos (enfoque } \\
\text { pedagógico integral). }\end{array}$ & $\begin{array}{c}40 \\
24 \\
10 \\
1 \\
0\end{array}$ & $\begin{array}{c}53,3 \% \\
32,0 \% \\
13,3 \% \\
1,3 \% \\
0,0 \%\end{array}$ \\
\hline
\end{tabular}


La tabla 8, muestra la información de los ítems del 17 al 23, relacionados a las prácticas de enseñanza realizadas por parte de los docentes de ciencias empresariales durante la pandemia. Se halló que para el ítem 17, entre las alternativas muy de acuerdo y algo de acuerdo que el $96,0 \%$ de los encuestados avanzó como docente en las prácticas de enseñanza de manera virtual fueron útiles, significativas $y$ creativas. En el caso del ítem 18, el 97,4\% de los docentes están muy de acuerdo y algo de acuerdo en ajustar las prácticas de enseñanza que comúnmente emplean como resultado de la pandemia y la necesidad de adelantar una educación mediada por TIC o virtual. Respecto al ítem 19 , el $85,6 \%$ en las mismas alternativas antes precisadas consideraron que hay objetos de conocimiento y competencias que no pueden ser trabajados de manera eficaz en el marco de la educación virtual o mediada por TIC. En lo relativo al ítem 20 , el $85,3 \%$ de los encuestados sienten que las prácticas de enseñanza han mejorado como resultado de la imposición de la educación virtual o mediada por TIC.

Donde se comprobó (ítem 21), que los participantes consideraron estar de acuerdo y muy de acuerdo que sus prácticas de enseñanza se ubicaron principalmente en un $44,0 \%$ en la pedagogía cognitiva (constructivismo, aprendizaje significativo, y similares). Mientras que otro grupo, comprendido por el $42,7 \%$ de los encuestados señalaron que su práctica de enseñanza se alimenta de distintos enfoques pedagógicos (enfoque pedagógico integral). El resto, un $13,3 \%$ las praxis la sitúan en la pedagogía crítica enfocada en la autonomía y emancipación del sujeto en razón de las necesidades de su contexto en lo social, político, económico y cultural.

Lo hallado en los ítems 17, 18, 19, 20 y 21 , evidencia que las prácticas digitales de docentes afectan tanto la necesidad de adelantar una educación mediada por TIC, así como avanzar en las praxis pedagógicas en línea, y la brecha entre estas dos áreas, que han disminuido. La enseñanza virtual se está convirtiendo en algo habitual y los docentes se adaptaron abruptamente empujados a experiencias, sin diseño ni preparación, en una docencia que es a distancia (García Aretio, 2021). A pesar de los grandes desafíos que plantea COVID-19, la crisis es una oportunidad para transformar y reimaginar la enseñanza virtual y comenzar a realizar una nueva visión para el futuro de la enseñanza en línea con procesos que incluyan una presencia cognitiva, social y del docente (Garrison, Anderson y Archer, 2000).

Tabla 9. Metodologías implementadas

\begin{tabular}{|c|c|c|c|}
\hline Ítem & Opciones & No & Porcentaje \\
\hline $\begin{array}{l}\text { 22. ¿La metodología empleada en el proceso } \\
\text { de enseñanza es novedosa y creativa, } \\
\text { superando la tradicional clase de 'explicar } \\
\text { el tema', 'aplicar ejercicios' y 'resolver } \\
\text { preguntas? } \\
\text { 23. ¿Empleo metodologías diversas como } \\
\text { la clase invertida, el método de las } 5 \mathrm{E} \text {, el } \\
\text { método del enfoque apreciativo, o similares? }\end{array}$ & $\begin{array}{l}\text { Muy de acuerdo } \\
\text { Algo de acuerdo } \\
\text { Ni de acuerdo ni en desacuerdo } \\
\text { Algo en desacuerdo } \\
\text { Muy en desacuerdo } \\
\text { Muy de acuerdo } \\
\text { Algo de acuerdo } \\
\text { Ni de acuerdo ni en desacuerdo } \\
\text { Algo en desacuerdo } \\
\text { Muy en desacuerdo }\end{array}$ & $\begin{array}{r}44 \\
27 \\
4 \\
0 \\
0 \\
0 \\
24 \\
38 \\
10 \\
2\end{array}$ & $\begin{array}{r}58,7 \% \\
36,0 \% \\
5,3 \% \\
0,0 \% \\
0,0 \% \\
32,0 \% \\
50,7 \% \\
13,3 \% \\
2,7 \% \\
1,3 \%\end{array}$ \\
\hline
\end{tabular}


En el ítem 22 de la tabla 9, se identificó que los entre las alternativas muy de acuerdo y algo de acuerdo que los docentes consideran en un $94,7 \%$ que la metodología empleada en el proceso de enseñanza llevada a cabo durante la pandemia es novedosa y creativa, superando la tradicional clase de 'explicar el tema', 'aplicar ejercicios' y 'resolver preguntas'. En cuanto al ítem 23, se conoció entre las mismas opciones que un $82,7 \%$ de los encuestados empleó metodologías diversas como la clase invertida, el método de las $5 \mathrm{E}$, el método del enfoque apreciativo, o similares. El resto, un 13,3\% se mantuvo neutral a tal afirmación mientras que un $4,0 \%$ estuvo en algo en desacuerdo y muy en desacuerdo ante el empleo de estas metodologías
Los hallazgos demuestran que los estudiantes ya están experimentando el aprendizaje en línea con diferente modelo utilizado por los docentes de ciencias empresariales. Sin embargo, la educación virtual conlleva que la inserción de métodos de enseñanza varía considerablemente entre uno a otro. Al contrastarlo con el ítem 21, estos modelos de teorías del aprendizaje la constructivista y aprendizaje significativo (ver tabla 8) la cuales fueron las más utilizadas, lo cual coincide con García Aretio (2020) que tras la pandemia, vienen surgiendo numerosas variantes y propuestas. De allí el reto y desafío de una definitiva necesidad de reorganizar las modalidades de enseñanza en la facultad de ciencias empresariales.

Tabla 10. Materiales y medios

\begin{tabular}{|c|c|c|c|}
\hline Ítem & Opciones & No & Porcentaje \\
\hline $\begin{array}{l}\text { 24. ¿Utilizó en los procesos de enseñanza } \\
\text { herramientas digitales como Kahoot, } \\
\text { Padlet, Wooclap,Wix, Jamboard, Genially, } \\
\text { entre otros? } \\
\text { 25. ¿Empleo en mis procesos de } \\
\text { enseñanza textos académicos en español } \\
\text { y otros idiomas para la formación de los } \\
\text { estudiantes? } \\
\text { 26. ¿Empleo en mis procesos de enseñanza } \\
\text { recursos audiovisuales para fortalecer la } \\
\text { formación de los estudiantes? }\end{array}$ & $\begin{array}{l}\text { Muy de acuerdo } \\
\text { Algo de acuerdo } \\
\text { Ni de acuerdo ni en desacuerdo } \\
\text { Algo en desacuerdo } \\
\text { Muy en desacuerdo } \\
\text { Muy de acuerdo } \\
\text { Algo de acuerdo } \\
\text { Ni de acuerdo ni en desacuerdo } \\
\text { Algo en desacuerdo } \\
\text { Muy en desacuerdo } \\
\text { Muy de acuerdo } \\
\text { Algo de acuerdo } \\
\text { Ni de acuerdo ni en desacuerdo } \\
\text { Algo en desacuerdo } \\
\text { Muy en desacuerdo } \\
\text { Muy de acuerdo } \\
\text { Algo de acuerdo } \\
\text { Ni de acuerdo ni en desacuerdo } \\
\text { Algo en desacuerdo } \\
\text { Muy en desacuerdo }\end{array}$ & $\begin{array}{r}26 \\
23 \\
12 \\
6 \\
8 \\
36 \\
32 \\
4 \\
3 \\
0 \\
53 \\
19 \\
3 \\
0 \\
0 \\
0 \\
55 \\
18 \\
2 \\
0 \\
0\end{array}$ & $\begin{array}{r}34,7 \% \\
30,7 \% \\
16,0 \% \\
8,0 \% \\
10,7 \% \\
48,0 \% \\
42,7 \% \\
5,3 \% \\
4,0 \% \\
0,0 \% \\
70,7 \% \\
25,3 \% \\
4,0 \% \\
0,0 \% \\
0,0 \% \\
73,3 \% \\
24,0 \% \\
2,7 \% \\
0,0 \% \\
0,0 \%\end{array}$ \\
\hline
\end{tabular}

Fuente: elaboración propia 
La tabla 10 muestra los resultados de los ítems del 24 al 27, los cuales dan cuenta de los medios y recursos utilizados por docentes de ciencias empresariales. Donde se comprobó (ítem 24) que el $65,4 \%$ de los encuestados estuvieron algo de acuerdo y muy de acuerdo en utilizar herramientas digitales como Kahoot, Padlet, Wooclap,Wix, Jamboard, Genially, entre otros, en los procesos de enseñanza. Otro grupo conformado por el $18,7 \%$ de los participantes expresaron estar algo en desacuerdo y muy en desacuerdo en manejar dichas herramientas. El resto $(16 \%)$, permaneció imparcial al respecto. En lo relativo al ítem 25, se determinó que el $90,7 \%$ de los docentes manifestaron estar muy de acuerdo y algo de acuerdo con el empleo de textos académicos en español y otros idiomas para la formación de los estudiantes en los procesos de enseñanza. En cuanto al ítem 26 , se conoció que el $96,0 \%$ usó en sus procesos de enseñanza recursos audiovisuales para fortalecer la formación de los estudiantes. Asimismo, en el ítem 27, se verificó que el 97,3\% administró en sus procesos de enseñanza recursos tecnológicos para mejorar las presentaciones o la forma en que se presenta la información.

Atendiendo estos ítems (24, 25, 26 y 27) se deduce que la enseñanza virtual está basada en aplicaciones de tecnologías de telecomunicaciones para brindar oportunidades de comunicación sincrónica y asíncrona. Además, utiliza tecnologías de la información y la comunicación (TIC) para brindar interacción además de la entrega de contenido. Hay dos aspectos de la interactividad en el uso de las TIC: la interactividad entre el estudiante y el contenido (materiales multimedia interactivos, así como en la Web) y la interactividad entre profesores y estudiantes y entre estudiantes. De allí que, se requiere un proceso complejo que va desde el uso hasta la adopción y apropiación. ya que la naturaleza interactiva de Internet, es comprensible que se incluya ampliamente recursos de la Web 2.0, esto denota la adaptación al desafío de los docentes a los procesos formativos y basada en la Web, en una enseñanza con la integración que ofrecen las TIC (Rueda, Luna Avendaño, 2021), que circunscribe autoaprendizaje, aprendizaje conectado y flexible, (Arboleda y Rama, 2013), pero el desafío es incluir todo ello a un aprendizaje que sea flexible.

Tabla 11. Incremento de tiempos para la docencia

\begin{tabular}{|c|c|c|c|c|}
\hline & Ítem & Opciones & No & Porcentaje \\
\hline & 28. ¿Considero que como resultado & & & \\
\hline$\frac{0}{\varepsilon} \cdot \frac{\pi}{0}$ & por TIC, han aumentado los & Muy de acuerdo & 58 & $77,3 \%$ \\
\hline \begin{tabular}{ll}
$=$ & \multicolumn{1}{c}{} \\
0 & 0 \\
0 & 0
\end{tabular} & tiempos de trabajo docente para & Algo de acuerdo & 14 & $18,7 \%$ \\
\hline $\begin{array}{ll}0 \\
0 \\
0 & 0 \\
0 & 0 \\
& 0\end{array}$ & la planificación y acompañamiento & Ni de acuerdo ni en desacuerdo & 3 & $4,0 \%$ \\
\hline 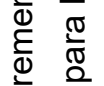 & estudiantil? & Algo en desacuerdo & 0 & $0,0 \%$ \\
\hline$\subseteq$ & & Muy en desacuerdo & & \\
\hline 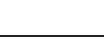 & & & 0 & $0,0 \%$ \\
\hline
\end{tabular}

Fuente: elaboración propia 
La tabla 11, muestra en el ítem 28 , que el $96,0 \%$ de los docentes encuestados consideraron estar algo de acuerdo y muy de acuerdo que ha aumentado los tiempos de trabajo docente para la planificación y acompañamiento estudiantil como resultado de la educación virtual o mediada por TIC, el resto se mantuvo neutral $(4,0 \%)$.

Adicionando otros desafíos, incluidos los conocimientos tecnológicos y las prácticas de enseñanza mediadas con TIC, se encuentra el tiempo de trabajo. Una buena práctica de enseñanza virtual requiere tiempo, y a su vez, utilizar métodos asíncronos y síncronos. No es solo el uso de una herramienta digital, es la apropiación y adopción de la misma para preparar los contenidos antes de la clase y asegurar que el educando esté preparado para su clase sincrónica con profesor en tiempo real. El desafío y reto es lograr que los docentes reflexionen, investiguen y perciban que los procesos didácticos o de formación mediados por la tecnología demandan de la presencia cotidiana con la tecnología (Oviedo, 2014)

Ítem 31. Dificultades en las prácticas y medios para la enseñanza de los docentes.

La pandemia ha reevaluado cómo los docentes dividen su tiempo entre la enseñanza, las tareas administrativas y las interacciones con los estudiantes. Bajo esta forma de enseñar, obviamente las actividades han aumentado el tiempo de trabajo, ello se expresa así:

\section{Sujeto36: Las actividades}

de preparación de clase, de

evaluaciones y calificaciones ha

aumentado debido a que me hace

falta explorar otras herramientas tecnológicas.

Sujeto28: El tiempo se ha convertido en tiempo completo dedicado al estudiante.
Se infiere, que la instrucción tradicional aún sigue vigente en los estudiantes y algunos profesores. La adaptación a las praxis pedagógicas en el contexto virtual, ha demostrado ser esencial, los modelos tradicionales de conferencias en persona no se trasladan en la enseñanza virtual independientemente del medio (laptop, PC, tablet, móvil) y las herramientas digitales (zoom, team, etc) que se utilice, pues, no solo enfrentan las condiciones del ambiente de aprendizaje sino dificultades técnicas, acceso a internet de los estudiantes y del mismo docente, tal y como lo demuestran los sujetos
Sujeto 38 y 39: Que no hacen los talleres a tiempo y buscan disculpas y el control de la presencia de los estudiantes durante el tiempo que dura cada clase.
Sujeto10: Creo que la educación virtual a veces tiene falencia como la conexión y la participación de los estudiantes al momento de retroalimentación

Se hace visible la disyunción que presenta la enseñanza virtual durante la pandemia. Predomina aquí, lo sincrónico en el proceso de enseñanza y aprendizaje y se torna indudable cuando los sujetos expresan las siguientes dificultades:

Sujeto64: Débil participación de los estudiantes en el desarrollo del programa.

Sujeto 24: El estudiante no quiere adaptarse a estos nuevos cambios Sujeto40: La entrega oportuna los trabajos

Sujetos 42: inasistencia Sujeto 35: La participación activa en clase, validando la asistencia del estudiante. 
A su vez, la adaptabilidad del nuevo ambiente o espacio de aprendizaje, es decir, pasar de la interacción cara a cara a la enseñanza virtual síncrona. De igual manera, sobresale el compromiso, la dedicación y la inasistencia de los estudiantes que asocian dificultades de los medios y recursos.

\section{Sujeto2: La mayor dificultad es que en ocasiones no sabemos si el estudiante está comprometido con la clase. \\ Sujeto7: La respuesta académica de los estudiantes}

Se detalla una asociación cognitiva en los profesores que enseñan, en el área de ciencias empresariales. Estos docentes no ven la necesidad de desarrollar una red de conexiones y significados que conecten con otros nodos de conocimiento (personas y sitios). Por tanto, no lo aplican en sus prácticas de enseñanza y en la modalidad asociada a las TIC, menos la ejecutan en su metodología implementada en su contexto,

Sujeto 56: Implementación de aplicaciones didácticas virtuales

Independientemente que los educadores deben adaptar sus prácticas y ser creativos para mantener a los estudiantes involucrados, se encuentra también otras dificultades para asumir el aprendizaje virtual: a) desafíos de autorregulación por parte de los estudiantes $y$; b) desafíos de habilidades tecnopedagogica. Como lo dicen los sujetos en los comentarios finales:

Sujeto3: Me gustaría que nos capacitaran o la UFPS tuviera una aplicación gratuita para juegos, dinámicas.

Sujeto8: La educación virtual ha dejado entre ver las limitaciones que tienen tanto como docentes y estudiantes frente a la revolución
4.0 que exige el mundo, pero sin recursos sostenibles en el tiempo para adquirir esa cultura.

Sujeto24: La virtualidad es un hecho y no se debe dejar pasar como parte del aprendizaje y de la toma del conocimiento.

Sujeto41: Estamos en una situación coyuntural que ha cambiado las formas de relacionarnos. Esta situación ha brindado la oportunidad para adaptarnos, siendo creativos, aprendiendo y aplicando herramientas que favorecen los procesos de aprendizaje.

Para impulsar la enseñanza de las ciencias empresariales en los nuevos tiempos se deberán aplicar aquellas iniciativas de enseñanza que hayan demostrado ser efectivas durante la fase de enseñanza virtual, de aprendizaje a distancia e integrarlas en el plan de estudio regular de estas. Es fundamental empoderar a los docentes, invirtiendo en el desarrollo de las habilidades necesarias y la creación de capacidad para explotar todo el potencial del aprendizaje virtual, remoto y/o mixto; síncrono y asíncrono.

\section{CONCLUSIONES}

Comprender que la educación en tiempo de pandemia optó por mundo remoto, virtual y digitalizado, infiere habilidades y prácticas tecno-educativas, donde los docentes deben apuntar a esa dirección. En tal sentido desde los retos, desafíos, incluso limitaciones de quien enseña en lo virtual debe tener un destrezas y nociones que sobrepase la visión inmediata y se conecte con un mundo en avanzada, de allí su labor de incorporación la enseñanza virtual como parte de una dinámica educativa en construcción no solo para Colombia sino los docentes del mundo. Desde el punto de vista, de la praxis de enseñanza virtual debe haber una 
interrelación directa entre todo, ahí es de donde se experimentaron varios desafíos relacionados con la incorporación de medios y la calidad del uso de estas herramientas tecnológicas, lo que indica problemas de brecha digital.

Los resultados arrojaron que el docente de ciencias empresariales experimentó algunos desafíos, independientemente del área temática o en el semestre del programa de formación que se impartiera. Seis de cada siete de los profesores ciencias empresariales que enseñaron de manera virtual informaron que sus estudiantes no estaban atentos, preparados y con problemas de conexión a internet, otros grupos importante mencionó que no poseer habilidades de las tecnologías y aplicaciones requeridas, lo que puede parecer sorprendente para una generación de estudiantes que han crecido con la tecnología. No obstante, existen brechas digitales también en los estudiantes.

Los retos por venir en la enseñanza virtual de ciencias empresariales, es que los profesores deben adoptar y adaptar la tecnología a las necesidades formativas y fomentar la comunicación, la colaboración y la interacción entre los estudiantes. Para implementar los métodos de enseñanza y evaluación asociados a las TIC.

Se concluye que el reto de la enseñanza virtual en los profesores objetos de estudio será usar herramientas de telecomunicaciones para centrar en la calidad de la enseñanza. Al mismo tiempo, el desafío de hacerlo con una planificación mínima que aborde:

a) Gestión / organización. Definición de reglas básicas de la enseñanza, así como concertación de resultados de aprendizaje alcanzables para cada unidad temática. También, negociar el proceso y el ritmo del aprendizaje; y, al mismo tiempo, brindar apoyo y retroalimentación. b) Construcción de comunidad de aprendizaje. En la enseñanza virtual los estudiantes se necesitan unos de otros, por ello, es conveniente el diseño de actividades que requieran la colaboración de los estudiantes.

c) Comunicación. Teniendo en cuenta la carga de trabajo de la formación, es indispensable la comunicación con toda la clase, en la cual se puede aprovechar para dar evaluación formativa en el proceso. Es necesario un horario de trabajo y charlas en línea en diferentes días y horas de la semana; promover debates en línea en profundidad en los que los estudiantes interactúen entre sí sobre sus ideas y perspectivas; e identificar un canal de comunicación sustituto independiente del curso, para poder contactar con tus alumnos y que puedan comunicarse entre sí (WhatsApp, SMS, teléfonos).

d) Estrategias de enseñanza. Desarrollo de actividades sincrónicas y asincrónicas, actividades grupales e individuales, y entre diferentes tipos de enseñanza, donde los estudiantes incluyan razonamiento inductivo, preguntas abiertas, enseñanza por analogía, técnicas de mapeo de conceptos, resolución de problemas, sin olvidar la creación de una red personal de aprendizaje en el ámbito digital, así como aprendizaje colectivo.

\section{REFERENCIAS BIBLIOGRÁFICAS}

Álvarez, V.; Romero, S.; Gil, J.; Rodríguez, J.; Clares, J.; Asensio, I.; del-Frago, R.; García, B.; García, M., González, D.; Guardia, S.; Ibarra, M.; López, R.; Rodríguez, G., Salmeron, P. (2011). Necesidades de formación del profesorado universitario para la adaptación de su docencia al Espacio Europeo de Educación Superior (EEES). RELIEVE, 17(1). DOI: https:// doi.org/10.7203/relieve.17.1.4122 
Arboleda, N. y Rama, C. (2013). La educación superior a distancia y virtual en Colombia: nuevas realidades. [Libro en línea]. Asociación Colombiana de Instituciones de Educación Superior con Programas a Distancia y Virtual, ACESAD, Bogotá. Disponible: https://virtualeduca.org/documentos/ observatorio/la educacion superior a distancia y virtual en colombia nuevas realidades.pdf

Arias, F. (2012). El Proyecto de Investigación. Introducción a la metodología científica. 6ta. Edición. Edición. Editorial EPISTEME, C.A. Caracas - República Bolivariana de Venezuela.

Avendaño, W. R., Hernández-Suárez, C., \& Prada-Núñez, R. (2021). El docente universitario ante la emergencia educativa. Adaptación a las TIC en los procesos de enseñanza. Educación y Humanismo, 23(41), Article 41. https:// doi.org/10.17081/eduhum.23.41.4354

Avendaño, W., Rueda, G., \& Paz, L. (2017). La investigación formativa en las prácticas docentes de los profesores de un programa de contaduría pública. Cuadernos de Contabilidad; Vol. 17, Núm. 43 (2016). https://doi. org/10.11144/Javeriana.cc17-43.ifpd

Burgos, C., Vázquez, E., López, E., \& Adaos, R. (2021). PROYECTO DIFPRORET: Análisis de las dificultades, propuestas $y$ retos educativos ante el COVID-19. IJERI: International Journal of Educational Research and Innovation, 15, 17-34. https://doi.org/10.46661/ ijeri.5145
Cardona, L. M. (2021). Percepciones de docentes frente al cambio en tiempos de pandemia. Educación Y Ciencia, 25, e12515-e12515. https://doi. org/10.19053/0120-7105.eyc.2021.25. e12515

Ellis, T. J., \& Hafner, W. (2003). Engineering an online course: applying the 'secrets' of computer programming to course development. British Journal of Educational Technology, 34(5), 639650. https://bera-journals.onlinelibrary. wiley.com/doi/full/10.1046/j.00071013.2003.00356.x

Fairstein, G y Gyssels, S. (2003). ¿Cómo se enseña? Colección "Programa Internacional de Formación de Educadores Populares". Caracas: Fe y Alegría

Fernández-Sánchez, M.-R., \& ValverdeBerrocoso, J. (2014). Comunidades de práctica: Un modelo de intervención desde el aprendizaje colaborativo en entornos virtuales. Comunicar: Revista Científica de Comunicación y Educación, 21(42), 97-105. https://doi. org/10.3916/C42-2014-09

García Aretio, L. (2001). La educación a distancia. De la teoría a la práctica. Barcelona, Ariel. https://dialnet.unirioja. es/servlet/articulo?codigo $=5407080$

GarcíaAretio, L. (2003). La educación a distancia. Una visión global. Publicado en el Boletín llustre Colegio de Doctores y Licenciados de España. № 146, pp. 13-27, https:// www2.uned.es/catedraunesco-ead/ articulos/2003/la $\% 20$ educacion $\% 20$ a\%20distancia\%20una\%20vision $\% 20$ global.pdf 
García Aretio, L. (2021). COVID-19 y educación a distancia digital: Preconfinamiento, confinamiento y posconfinamiento. RIED. Revista Iberoamericana de Educación a Distancia, 24(1), 09-32. https://doi.org/10.5944/ried.24.1.28080

Garrison, D. R., Anderson, T., \& Archer, W. (2000). Critical inquiry in a text-based environment: Computer conferencing in higher education model. The Internet and Higher Education, 2(2-3), 87-105. Disponible: http://citeseerx.ist.psu.edu/ viewdoc/summary?doi=10.1.1.525.9388

Henry, J., \& Meadows, J. (2008). An absolutely riveting online course: Nine principles for excellence in web-based teaching. Canadian Journal of Learning and Technology. https://doi.org/10.21432/ T20C7F

Hernández Sampieri, R., Fernández Collado, C., \& Baptista Lucio, P. (2014). Metodología de la Investigación. Sexta Edición. McGraw-Hill/Interamericana Editores, S.A. de C.V.

Hernández-Sampieri, R., \& Mendoza, C. P. (2018). Metodología de la investigación: Las rutas cuantitativa, cualitativa $y$ mixta. McGraw-Hill Education.

Koehler, M., \& Mishra, P. (2009). ¿What Is Technological Pedagogical Content Knowledge? Contemporary Issues in Technology and Teacher Education, 9(1), 60-70.

Lassos, E., Munévar, P., Rivera, J., \& Sabogal, A. (2017). Estado del arte sobre la articulación de modelos enfoques y sistemas en educación virtual. Universidad Nacional Abierta Y a Distancia,. https://hemeroteca. unad.edu.co/index.php/book/article/ view/1969
Martínez Uribe, C. (2008). La educación a distancia: Sus características y necesidad en la educación actual. Educación, 17(33), Article 33. http:// revistas.pucp.edu.pe/index.php/ educacion/article/view/1532

Naciones Unidad (2020). Note de synthese : l'education en temps de covid-19 et apres

Oviedo, P (2014). El docente ante los desafíos del siglo XXI, en Oviedo, P. (compilador) (2014) Investigaciones y desafíos para la docencia del siglo XXI. Consejo Latinoamericano de Ciencias Sociales (CLACSO). http:// biblioteca.clacso.edu.ar/Colombia/ fce-unisalle/20170117032546/ investigacion.pdf

Parra, J. (2005). Aproximación a la virtualidad desde la propuesta educativa de la Fundación Universitaria Católica del Norte, FUCN. En. Fundación Universitaria Católica del Norte (Compiladora). (2005), Educación virtual: Reflexiones y experiencias. $\mathrm{s} /$ Fundación Universitaria Católica del Norte. - Medellín: FUCN. https:// www.ucn.edu.co/institucion/salaprensa/Documents/educacion-virtualreflexiones-experiencias.pdf

Pratt. (s. f.). (PDF) Five Perspectives on Teaching: Ch 3 - Alternative Frames of Understanding. ResearchGate. Recuperado 27 de septiembre de 2020, de https://www.researchgate. net/publication/299579864_Five_ Perspectives_on_Teaching_Ch_3_-Alternative_Frames_of_Understanding 
Rama, C. (2007). La despresencialización de la educación superior en América Latina: ¿tema de calidad, de cobertura, de internacionalización o de financiamiento? Apertura, O(6). http:// www.udgvirtual.udg.mx/apertura/index. php/apertura/article/view/1216

Rueda, G., Luna, H. O, \& Avendaño, W. (2021). Estudiantes de pregrado frente a la educación mediada por TIC: Percepciones en contextos de pandemia. Revista Boletín Redipe, 10(8), 321-339. https://doi.org/10.36260/rbr.v10i8.1408

Sanabria, Z. (2020). Educación virtual: Oportunidad para «aprender a aprender». Fundación Carolina. https:// www.fundacioncarolina.es/educacionvirtual-oportunidad-para-aprender-aaprender/

Sarmiento, M. (2007). La enseñanza de las matemáticas y las Ntic. Una estrategia de formación permanente. [Http://purl. org/dc/dcmitype/Text, Universitat Rovira i Virgili]. https://dialnet.unirioja.es/ servlet/tesis?codigo $=8262$

Siemens, G. (2006). Knowing knowledge. (Null). Lulu Press.

Spector, C., Figueira, J., Miramontes, C., \& Canova, C. (2020). Enseñanza y evaluación a distancia en época de pandemia: Experiencia inicial de las Carreras de Salud de UCES. 9, 7-18.

Universidad Francisco de Paula Santander - UFPS. (2017). Proyecto Ecucativo del Programa de Contaduría Pública. PEP. Cúcuta, Colombia. https://ufpso. edu.co/ftp/pdf/pep/Anexo\%2001.\%20 Proyecto $\% 20$ Educativo $\% 20$ del $\% 20$ Programa.pdf 